\title{
PREVENTION OF ISCHAEMIC HEART DISEASE
}

\author{
Report of a Joint Services Symposium held in 1979 at the \\ Royal Army Medical College
}

Edited by

BRIGADIER J P CROWDY

\section{Director of Army Preventive Medicine}

\section{Introduction}

The symposium reported in these pages was held with a three-fold purpose; first to consider the importance to the Services of ischaemic or coronary heart disease (IHD or CHD) as a cause of morbidity and mortality; second, to review the relevance of the known risk factors to life in the Armed Forces; and third perhaps most important of all - to make recommendations for preventive measures.

An audience of some 60 doctors gathered for the meeting, representing all branches of the medical services of the Navy, Army and Royal Air Force (RAF). In addition there were present representatives from the Directorate of Civilian Medical Services, the Civil Service Medical Adviser's office and also two doctors from the Euromed organization.

Thirteen papers were presented, 10 from serving medical officers and three from distinguished visitors. At the end of the day the general discussion, chaired by Major General H A J Reay (then Postgraduate Dean), attempted to identify priorities for active intervention and preventive action.

The day-long duration of the meeting precludes publication of the presented papers in full and it has thus been necessary to print them in summarized form.

\section{The Background; epidemiology, pathogenesis and military significance}

RECENT ADVANCES IN EPDEMIOLOGY PROFESSOR GEOFFREY ROSE, DM, FRCP, FFCM Time trends

After years of seemingly inexorable rises, the situation now looks more cheerful. In Britain mortality in male doctors is falling, and in Social Class 1 as a whole (though not in other classes) it has at least stopped rising. Thus the traditional "upper class" image no longer applies, and rates are now much higher in working class men. In our Whitehall Study of civil servants we found CHD mortality in "messengers" to be more than three times that in "administrators".

In the United States of America (USA) the last 10 years have seen a decline of more than 25 per cent in CHD mortality, involving all age groups, men and 
women, blacks and whites. The explanation is unknown, partly due to inadequate monitoring of relevant risk factors. Improvements in treatment of acute attacks, even if universally available, could not account for more than about a 5 per cent fall in deaths, this being the ratio of primary ventricular fibrillation in hospital to all CHD deaths. Cardiac surgery also can only have made a small contribution: at best it offers a few years extra life to 10-20 per cent of suitable patients, who form only a minority of total cases. There are good hopes that recent medical advances in secondary prevention may soon make a larger contribution, at least in delaying deaths.

\section{Sudden death}

Primary ventricular fibrillation, occurring early in the acute attack, remains a baffling problem. The myocardium in such cases often shows no major ischaemic damage: when resuscitation is successful, some 60 per cent do not develop infarction (although attacks are liable to recur). Most coronary ambulance services have not been very successful, due to difficulty in arriving soon enough (largely because of patients' delay in seeking help); most cases of "collapse" are not coronary, but diagnostic confirmation loses precious time.

\section{'Intermediate' prevention}

Annual examinations by sympton-questionnaire and ECG can give advance warning of most acute attacks. In the Whitehall Study a single examination, lasting only $2 \frac{1}{2}$ minutes, identified 14 per cent of men as 'suspect ischaemia'. among whom occurred 49 per cent of all CHD deaths in the next five years. Intervention at this stage (intermediate between primary and secondary prevention) has great potential: but it remains to be shown what action is effective and safe.

\section{Primary prevention}

Clinicians naturally concentrate their efforts on high-risk individuals, especially those with high values of single factors (BP, cholesterol, etc.). However good for the individuals concerned, this policy can have little impact on the total community problem: most cases of CHD occur in those with slight (often inconspicuous) elevation of several factors. There is far more potential for mass measures which would lower the whole population distribution of a risk factor. In the Whitehall Study, for example, a lowering of the BP distribution by only $7.5 \mathrm{~mm}$ might be expected to prevent as many deaths as a treatment policy which was able to normalise the risk of every individual with a diastolic (phase 5) pressure of $105 \mathrm{~mm}$ or more. Thus the impact of small changes affecting large numbers of people could be surprisingly big.

The evidence on selecting those changes appropriate for community-wide implementation has neither been weakened nor greatly increased in the last five years: priority should still go to moderation of dietary saturated fat, abandonment of cigarettes, regular exercise (preferably vigorous), and perhaps also the control of overweight. 
In any mass preventive effort only a small minority can hope to benefit from a particular measure; but the rest, in large numbers, are exposed to many hazards. In the recent trial of clofibrate in primary prevention the benefits from a reduced incidence of myocardial infarction were outweighed by a quite unforeseen excess of deaths from other causes in subjects receiving clofibrate. For any mass preventive measure it is essential to have a reasonable assurance that the risk of adverse effects is extremely small, and this practically rules out mass medication. The main hope rests with mass behavioural change.

\section{PREVALENCE AND IMPORTANCE IN THE ROYAL NAVY SURG CDR A M HAZELL, MB, MRCP, RN}

Between 1860-64 there were 189 deaths from heart disease amongst Naval personnel, whereas, between 1970-74 there were only 57, 50 of these being from ischaemic heart disease.

Ischaemic heart disease accounts for approximately 0.25 per cent of all hospital admissions in the Royal Navy (RN), but the length of inpatient stay for these patients is twice the average. The number of cases is roughly twice that of other types of heart disease, but only half that of hypertension.

Ratings are affected approximately three times more commonly than officers when the figures are standardized for age, and they have about the same death rate as an equivalent civilian population. Officers have only 41 per cent of the death rate of ratings and civilians.

Ischaemic heart disease accounts for approximately 0.25 per cent of morbidity, 1 per cent of invalidings and 10 per cent of deaths in the Royal Navy. However, its importance is considered to be disproportionately great.

The incidence rises with age and affects the more senior and highly trained personnel who are often in the terminal stages of their service career. Few are able to resume completely normal service duties, and their future outside the Royal Navy is unknown.

\section{PREVALENCE AND IMPORTANCE IN THE ARMY \\ LT COL P J BLACKBURN, MA, MB, MFCM, RAMC}

In 1977 in England as a whole ischaemic heart disease (IHD) caused some 145,000 deaths accounting for 27 per cent of all deaths. This percentage has not changed since 1968, and it is relevant to question how this modern epidemic affects the Army, which attempts to select the most healthy for its recruits and thereafter expects a high standard of physical fitness from its members. An earlier investigation had suggested that male Army officers had a better than expected mortality from IHD during a ten year period ending in 1971, by comparison with male mortality in England and Wales. For this reason it was decided to compare observed and expected male mortality rates for the Army as a whole over a five year period, and the findings are shown in Table $I$. 